assumptions with respect to scale interpretation and statistical analyses.

\section{G STUCKI} S STUCKI

P BRÜHLMANN B A MICHEL

Department of Rheumatology and Physical Medicine, University Hospital, Zürich, Switzerland

1 Wright B D. Solving measurement problems with the Rasch model. $\mathcal{f}$ Educ Res 1977; 14: 97-116.

2 Silverstein B, Fisher W P, Kilgore K $M$, Harley J P, Harvey R F. Applying psychometric criteria to functional assessment in medical rehabilitation: II. Defining interval measures. Arch Phys Med Rehabil 1992; 73: 507-18.

3 Merbitz C, Morris J, Grip J C. Ordinal scales and foundations of misinference. Arch Phys Med Rehabil 1989; 70: 308-12.

\section{Epidemiology of adult Still's disease}

We read with interest the study by MagadurJoly and colleagues about the epidemiology of adult Still's disease (ASD) published recently in Annals. ${ }^{1}$ We would like to describe a patient who was significantly older than the age incidence mentioned in their study and posed considerable diagnostic difficulty.

A 66 year woman was referred urgently by her general practitioner with a two week history of sore throat, fever, weight loss, arthralgia/myalgia, and a rash. Apart from a history of hypertension she had previously been well.

When examined, she had a non-suppurative pharyngitis, a generalised polyarthritis with bilateral knee joint effusions and wrist and ankle joint synovitis bilaterally. She had an erythematous macular rash affecting her arms, legs, and trunk. She was pyrexial, with a temperature of $40^{\circ} \mathrm{C}$. There was no obvious site of infection. Examination of the abdomen was normal; in particular, there was no hepatosplenomegaly. Investigation revealed erythrocyte sedimentation rate $123 \mathrm{~mm} / 1 \mathrm{st}$ $h$, haemoglobin $12 \cdot 5 \mathrm{~g} / \%$, leucocyte count $28.6 \times 10^{9} / 1$ (differential count, $94 \%$ polymorphs), mildly increased concentrations of urea and creatinine $(16.6 \mathrm{mmol} / \mathrm{l}$ and 169 $\mu \mathrm{mol} / 1$, respectively), and normal liver function. Throat swab, blood cultures, and midstream urine were negative. Antistreptolysin $\mathrm{O}$ was normal. Echocardiography, electrocardiogram, and chest radiograph were normal. She was negative for rheumatoid factor, antinuclear factor and antineutrophil cytoplasmic antibodies on two occasions. Serum ferritin concentration was $17952 \mu \mathrm{g} / \mathrm{l}$ (normal range 15-200).

Over the next two weeks, the patient remained pyrexial, with her temperature peaking consistently in the evenings with recrudescence of her rash. Her joint symptoms initially responded to nonsteroidal anti-inflammatory agents, but she continued to be pyrexial. Her temperature persisted despite administration of aspirin, and she was prescribed prednisolone enteric $60 \mathrm{mg} / \mathrm{day}$, with resolution of the rash and pyrexia.

A diagnosis of ASD was made on the basis of the clinical features and exclusion of other pathology. She was discharged home, taking steroids and aspirin, and on subsequent review in clinic was greatly improved, with almost complete resolution of her rash and fever.

This patient illustrates several important clinical points, not stressed in the article published by Magadur-Joly and colleagues, but important for any future prospective studies on incidence. First, the diagnosis of ASD is often very difficult to make. Second, it is a diagnosis of exclusion. Third, given the rarity of the condition, diagnosis may be further delayed in patients of this age, though there are reports of ASD in this age group. ${ }^{23}$

Furthermore, the study by Magadur-Joly's group gave an approximation of the incidence of this disease in a French population obtained by written survey. We suspect that many cases of ASD are mild and go undiagnosed. Identification of such cases would therefore be difficult in any prospective study on ASD. Clearly, what is required is greater awareness of the disease and further research into its pathogenesis, in addition to prospective studies on incidence.

\section{CIARAN A DUNNE JEFF DAVIES Department of Rheumatology, Broomfield Hospital, Broomfield, Chelmsford, Essex CM1 SET,
United Kingdom}

1 Magadur-Joly G, Billaud B, Barrier J H, et al. Epidemiology of adult Still's disease: estimate of the incidence by a retrospective study in west France. Ann Rheum Dis 1995; 54 587-90.

2 Wouters J M G W, van Rijswijk M H, van de Putte L B. Adult onset Still disease in the elderly: a report of two cases. $\mathcal{F}$ Rheumatol 1985; 12: 791-3.

3 Steffe L A, Cooke C L. Still's disease in a 70 year old woman. $\mathcal{F A M A} 1$ 1983; 249: 2062-3.

\section{AUTHORS' REPLY:}

Drs Dunne and Davies reported a case of adult Still's disease in an elderly patient and emphasised the difficulties of diagnosis, particularly in this age group. We share their opinion as to the difficulty of making a diagnosis of ASD, which is the reason why we used the criteria of Ohta et al (sensitivity $96 \%$; specificity $92 \%^{1}$ ) in all but one case. Nevertheless, in our experience diagnosis does not seem any more difficult in elderly patients: in our sudy we identified two patients who were 61 and 62 years old.

Drs Dunne and Davies suspect many cases of ASD to be mild. In our study we did not distinguish between mild ASD or full ASD, but required the symptoms to fit with the criteria of Ohta et al.

In conclusion, we agree that what is required is greater awareness of this disease, and we believe that making studies of its incidence is one approach to achieving progress towards that aim.

G MAGADUR-JOLY Service de Medicine Interne II, $C H U, B P 1005$ 44035 Nantes cedex 01, France

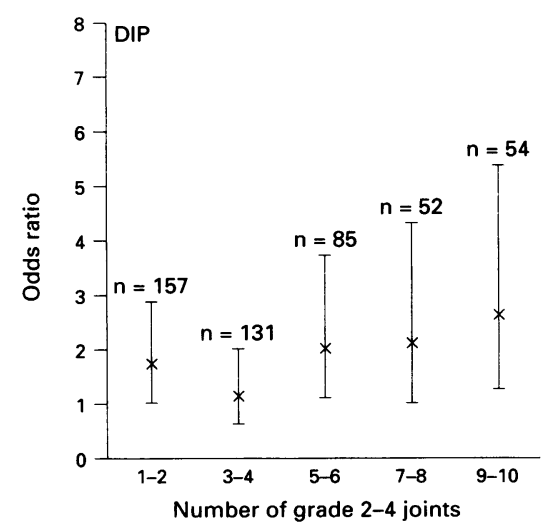

\section{LETTER TO THE EDITOR}

\section{Racial variation in rheumatoid arthritis}

MacGregor and colleagues ${ }^{1}$ reported a lower prevalence of rheumatoid arthritis in black Caribbeans than in white subjects in Manchester. There are grounds for supposing that one cause of RA is low testosterone levels. ${ }^{2}$ It has been reported that in the USA, black males have significantly higher testosterone levels than white males. ${ }^{3-5}$ A similar difference has been reported in the USA between (pregnant) black and white females. ${ }^{6}$ It seems likely that part of this racia variation of testosterone levels is not genetic.? Meanwhile, it would be interesting to know whether there is racial variation in testosterone level in this country.

$$
\begin{array}{r}
\text { WILLIAM H JAMES } \\
\text { MRC Mammalian Development Unit } \\
\text { Wolfson House } \\
\text { University College London } \\
\text { London NW1 } 2 H E \text {, United Kingdom }
\end{array}
$$

1 MacGregor A J, Riste L K, Hazes J M W Silman A J. Low prevalence of rheumatoid arthritis in Black Caribbeans compared with Whites in inner city Manchester. Ann Rheum Dis 1994; 53: 293-7.

2 James W H. Rheumatoid arthritis, the contraceptive pill and androgens. Ann Rheum Dis 1993; 52: 470-4.

3 Ellis L, Nyborg H. Racial/ethnic variations in male testosterone levels: a probable contrimale testosterone levels: a probable contri-
bution to group differences in health. Steroids bution to group

4 Ross R, Bernstein L, Judd H, Hanisch R, Pike $M$, Henderson B. Serum testosterone levels in healthy young Black and White men. $\mathcal{f}$ Nat Cancer Inst 1986; 76: 45-48.

5 Hill P, Wynder E L, Garnes H, Walker A R P Environmental factors, hormone status and prostatic cancer. Prev Med 1980; 9: 657-66.

6 Henderson B E, Bernstein L, Ross R K, Depue R H, Judd $\mathrm{H}$ L. The early in utero oestrogen and testosterone environment of Blacks and Whites: potential effects on male offspring $B$ f Cancer 1988; 57: 216-8.

7 James $\mathrm{W}$ H. Causes of racial differences in testosterone levels of men. $\mathcal{F}$ Natl Cancer Ins 1993; 85: 506 .

\section{Correction}

\section{Association of hand and knee}

osteoarthritis: evidence for a

polyarticular disease subset

Hirsch et al (Ann Rheum Dis 1996; 55: 25-29)

The publishers and typesetters apologise to the authors for errors that led to publication of a version of figure 3 that omitted point estimates shown in the orginal (below).

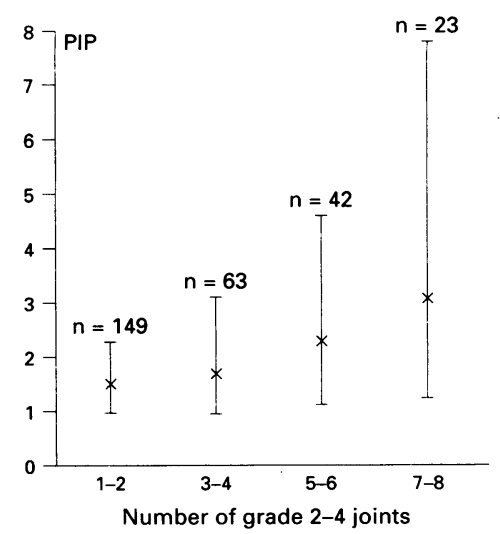

